\title{
Marginados y rebeldes: Juan Ruiz de Alarcón y Fernando Zárate Castronovo, autores de comedias \\ Marginalized and Rebellious: Juan Ruiz de Alarcón and Fernando Zárate Castronovo, Playwrights
}

\section{Margarita Peña}

Universidad Nacional Autónoma de México

MÉXICO

penamargarita261@gmail.com

[Hipogrifo, (issn: 2328-1308), 5.1, 2017, pp. 357-370]

Recibido: 06-10-2015 / Aceptado: 10-11-2015

DOI: http://dx.doi.org/10.13035/H.2017.05.01.23

Resumen. A partir de la comedia Mudarse por mejorarse de Juan Ruiz de Alarcón y Mudarse por mejorarse, de Fernando Zárate Castronovo (ca. 1663) se comparan estos autores en lo tocante al origen semita de ambos, rasgos personales, aspectos biográficos, acoso por parte de poetas y autores rivales contra el novohispano Ruiz de Alarcón, y persecución de Zárate por «marranismo». Se plantea la actitud cauta del marginado Alarcón frente a la actitud desafiante del rebelde Zárate, y el final contrastante de ambos autores. Como conclusión, es posible afirmar que Zárate Castronovo copió tan solo el título de la comedia alarconiana, de modo que pudiera relacionarse con el deseo inconsciente de «mudar» de aspecto físico (Alarcón) o de destino (Zárate).

Palabras clave. Autores teatrales, judíos, comedia, plagio, Siglo de Oro, jorobado, rivalidad, acoso, datos biográficos, Inquisición en España, Sevilla, prudencia, rebeldía.

Abstract. This article offers a comparison between two plays: Mudarse por mejorarse by Juan Ruiz de Alarcón y Mudarse por mejorarse by Fernando Zárate Castronovo (ca. 1663) in order to examine the authors' Jewish origins, personalities 
and biographies. Both of them suffered harassment from other authors (Alarcón) and from Spanish Inquisition (Zárate). Alarcón, who was an isolated but peaceful man, died in Madrid the 4th of August 1639. On the contrary, Zárate, who was rebellious and defeated, died at Sevilla's Inquisition Palace, the 18th of March 1663. As a conclusion, we can confirm that Zárate Castronovo just copied the title of Alarcón's comedy to be able to relate it to the unconscious desire of «change» the physical appearence (Alarcón) or the fate (Zárate).

Keywords. Playwrighters, Jewish, Play, Plagiarism, Golden Age, Hunchback, Rivalry, Harassment, Biographical Information, Rebellious, Spanish Inquisition, Sevilla.

Poco antes de la fecha de su muerte en 1663, Fernando Zárate Castronovo dio a la imprenta la comedia Mudarse por mejorarse, de título idéntico a la de Juan Ruiz de Alarcón que éste incluyera en la Primera Parte de sus comedias, impresa en Madrid, I628, por Juan González en casa de Alonso Pérez, con dedicatoria a don Ramiro Felipe de Guzmán, yerno del conde-duque de Olivares y virtual protector de Alarcón ${ }^{1}$. Mudarse por mejorarse es la sexta dentro del libro, marcaría el principio de escritura de comedias de Alarcón y el casi el final de Zárate Castronovo. En cuanto a Alarcón, Mudarse por mejorarse (que circuló en las colecciones de comedias también con los títulos de Por mejoría y Dejar dicha por más dicha) se imprime junto con La cueva de Salamanca, El semejante a sí mismo, La industria y la suerte, y otras que podrían considerarse primerizas, escenificadas en la Península. De acuerdo con Antonio Castro Leal pudo haber sido escrita entre 1617 y 1618, Alarcón ya de vuelta en Madrid tras su estancia de cinco años en la Ciudad de México (1608-1613), y representada en 1622². En el caso de Zárate Castronovo, la comedia Mudarse por mejorarse, impresa posiblemente ca. 1658, sería una especie de canto del cisne del autor que muere en 1663. Acosado en vida por la Inquisición, dos veces relajado en ausencia, finalmente minado en cuerpo y alma por males que en parte se deberían a su accidentado periplo existencial por Sevilla, Madrid, Burdeos, Rouen con el Santo Oficio pisándole los talones, alternando el comercio con el oficio de escritor, autor de novela, poesía, comedias. Males causados en parte por los avatares de la fuga perpetua; por una conciencia escindida entre el judaísmo heredado de su padre y el cristianismo profesado por su madre. Oscilación en la que al parecer triunfaría finalmente la adhesión al «marranismo» del padre, a las prácticas de la religión judaica, no sabemos si por convicción o por rebeldía ante el poder reinante. Zárate, un hombre dividido, como también lo fuera Ruiz de Alarcón. Éste, de padre cristiano viejo con pretensiones de hidalguía y madre de ascendencia judía, alternando entre dos países y dos continentes, con ras-

1. Parte Primera. De las comedias de don Juan Ruiz de Alarcón, Relator del Real Consejo de las Indias, por su Magestad. Dirigidas al Excelentísimo señor don Ramiro Felipe de Guzmán, señor de la casa de Guzmán, etc. Con Privilegio en Madrid, por Juan Gozález. Año 1628: A costa de Alonso Pérez Librero del Rey Nuestro S. [8., 4 fols, prs.+ 179 fols.]

2. Antonio Castro Leal, 1943, pp. 129 y ss. 
gos fisicos semíticos difíciles de ocultar y aparente confesión cristiana, una ética casi laica y habilidad para la simulación en cuestiones cardinales que tocaban a la raza y a la fe. Actitudes que se trasladan a los títulos de las comedias y caracterizan a algunos de sus personajes, en cierto modo remedos de él mismo y dan pie a la catarsis a través de la escritura. Sus títulos (títulos al uso, por lo demás) permiten entrever facetas de su personalidad: La verdad sospechosa, El semejante a sí mismo, Los empeños de un engaño, El desdichado en fingir, Mudarse por mejorarse. En colaboración con Tirso de Molina (o con Belmonte Bermúdez), Siempre ayuda la verdad. Duplicidad y engaño, denuncian los títulos; escarmiento y arrepentimiento consiguientes. Fingir, querer ser otro, alguien sin jorobas, sin lastres raciales heredados. Adelantemos que en Ruiz de Alarcón privan la simulación, el ocultamiento de los rasgos judaicos que le vienen de madre; ocultamiento que tiñe de titubeos y quizás de remordimiento. De ahí los temas y personajes de sus comedias: el de la mentira; el mentiroso engañador don García que linda con lo patológico y será escarmentado. Escarmiento que vendrá a redimirlo de la falta, el pecado de la mentira misma. En Ruiz de Alarcón, su creador, no habrá tal escarmiento pues delega la falta en su personaje y lo condena. De una manera racional, como se ha dicho que es su teatro, Alarcón construye su alter ego, y al condenarlo se libera de la carga de la mentira. ¿Arrepentimiento por transgredir uno de los diez mandamientos? No. Recurso necesario para disimular su herencia semita, salvarse de la suspicacia de sus enemigos y la suspicacia inquisitorial, premeditada, racionalmente. De la que no se salvará Zárate Castronovo (o Antonio Enríquez Gómez), quien alardea de su condición de criptojudío en sus hechos, tratos, escaramuzas, y lo delatan los trasfondos de su obra: teatro, poesía y prosa: Las misas de san Vicente Ferrer; Sansón Nazareno, Gregorio Guadaña, respectivamente. Mal se cuidará Enríquez Gómez, o Zárate Castronovo, de ocultar lo que se consideraba un estigma que había costado la vida al abuelo; más bien lo proclama (cuando habita en Burdeos en compañía de su tío Antonio Enríquez Mora). Es la suya una actitud de reto, desafío, ante una sociedad avasallada por el Tribunal del Santo Oficio: una suerte de provocación que a la larga pagará con la vida. Se ha dicho que el cambio de nombre, cuando abandona Rouen y regresa a España convertido en Zárate Castronovo, apunta más al empeño de esconderse de otros negociantes defraudados por él que a disimular su identidad. Instalarse en Sevilla; presenciar, arriesgándose oculto entre la muchedumbre, su propia quema en efigie suena escalofriante; en Toledo también lo quemarán en efigie. Y luego en Sevilla, lo prenden en su propia casa: diríamos, se deja prender. Tras 12 años de huida constante, una distracción suicida. Las cárceles secretas de la Inquisición en Triana, en las márgenes del Betis, debían ser más húmedas aun que las del Santo Oficio en México en las que los presos morían de enfermedades diversas, a veces sin que nadie se apercibiera. Tras el juicio y cautiverio, minado en cuerpo y alma, sucumbe el 18 de marzo de 1663. Pero no llegará a la hoguera, habrá protagonizado una huida más. Habrá escapado, por fin, de sus carceleros.

En cuanto a Ruiz de Alarcón, los títulos de sus comedias, con variantes, se suceden en la listas de comedias sueltas desglosadas o en colección impresas en los siglos XVII o XVIII y revelan una verdad autobiográfica. Pese a la caracterización de escritor moralista que reprueba la mentira -imagen difundida por la crítica tradi- 
cional, especialmente la crítica sajona - una lectura alternativa de Alarcón descubre a un hombre interiormente desasosegado, como sus personajes don García, o don Juan de Las paredes oyen, que saltan de la vida al escenario: seres y situaciones que él va a transmutar en teatro. Vendrían a ser algo así como los paratextos que darán paso al texto mismo de la comedia. Desasosiego existencial del autor debido en gran medida al defecto físico: una doble joroba en pecho y espalda. Desasosiego por su condición soslayada de descendiente de judíos conversos. Lo era por parte de madre novohispana con ascendientes judíos conversos, aunque cristiano por parte del padre Pedro Ruiz de Alarcón, nacido en $\mathrm{Cuenca}^{3}$. Una coincidencia ésta con Antonio Enríquez Gómez (o Fernando Zárate Castronovo), también de procedencia conquense. Y otra más, la existencia trashumante: Alarcón, nacido en el pueblo minero de Taxco, o Tlachco, Nueva España, en $1572^{4}$ según consta en la fe de bautismo, y estudiante en la Real y Pontificia Universidad de México, viajó a España por primera vez en 1600; apenas llegado a Salamanca se recibió de bachiller en Cánones ${ }^{5}$ (21 de octubre de 1600); se inscribió y cursó Leyes hasta 1604, viajó por algunos puntos de la Península. Residió en Sevilla en donde litigó y en 1608 -tras haberlo intentado sin éxito en 1607 por el ataque de los piratas holandeses a la flota- se embarcó de regreso a Indias. Luego, tras cinco años en la Ciudad de México en la que a poco de llegar (1609) obtuvo el grado de Licenciado en Leyes, «pretendiendo» sin éxito un puesto en la Universidad -en razón de su defecto físico, su doble joroba que lo «desayudaba»-cruzó por tercera vez el Atlántico, se instaló en la España de los Austrias, escribió más de veinte comedias y logró que se imprimieran $(1628,1634)$. Atacado de palabra y de hecho por escritores adictos a Lope de Vega y otros, marginado en el mundillo teatral, a partir de 1626 ocupó el puesto de relator del Consejo de Indias y murió en Madrid en 1639. Hasta donde sabemos, fue el único de cinco hermanos que cruzó el Atlántico. Una existencia la

3. El acta o partida de matrimonio de los padres de Ruiz de Alarcón encontrada, de acuerdo con L. Carranco Cardoso, por José María de Ágreda y Sánchez en el Sagrario de la Catedral de México, reza como sigue: «En domingo nueve días del mes de marzo de mil quinientos y setenta y dos años yo el cura ynfrascrito desposé por palabras de presente según orden de la Santa Madre Iglesia a Pedro Ruiz de Alarcón, hijo de García Ruiz y de doña María de Valencia, vezinos de Alvaradejo, con doña Leonor de Mendoza, la hija de Hernando de Mendoza y de Maria de Mendoza, vezinos de las minas de Tasco. Fueron presentes por todos ille señor doctor Luis de Vilanueva, oydor desta real Audiencia, y de Francisco de Velasco y don Luys de Velasco y Alonso de Villaseca. Francisco Moreno, Cura (p. 47)» (Peña, 2000, p. 86). 4. «En treinta de diciembre de 1572 años Alonso Torquemada semanero en la región de Tachco bautisé en la ermita de la Santa Veracruz, Real de Minas de Tetelcingo a Juan, hijo de Pedro Ruiz de Alarcón y Leonor de Mendoza, su mujer. Fueron testigos José de Cabra y María Josefa, su muger.-Cura semanero Alonso de Torquemada» (Peña, 2000, pp. 87-88).

5. [Universidad de Salamanca] Libro de Matrículas. AUS 312, 1599/1600, p. 215: «Doctores y maestros, Licenciados y cathedráticos desta Universidad los quales se matricula/ron víspera de Sancta Caterina: 24 de noviembre de 1599 en 1600». En fol. 65r.: «A 17 de octubre de 1600 Juan Ruiz de Alarcón natural de la ciudad de megico/ a 18 otubre 600/ $5^{\circ}$. años/»; «Estudiantes y bachilleres que dixeron ser en la facultad de Canones:/ este años (sic) de 1599 en/ 1600./[....] 21 de otubre de 1600. Juan Ruiz de Alarcón natural de la ciudad de México en la Nueua España. $1^{\circ}$.-/Bachiller a 21 de otubre 1600». En Libro de Matrículas, 313 AUS, Fondo Universitario, p. 219: «f. 64v.: a 24 de noviembre 1604, Juan Ruiz de Alarcon, Bc. BLta. Letrado natural de Mexico en Indias» (Peña, 2000, p. 219). 
suya trashumante a su manera; agitada, aunque no accidentada como la de Fernando Zárate Castronovo.

Antonio Enríquez Gómez (o Fernando Zárate Castronovo), autor de El siglo Pitagórico y vida de Gregorio Guadaña, Academias morales de las musas, Sansón Nazareno, y comedias -El maestro de Alejandro, entre otras - nacido en 1601, muerto en 1663, perseguido y condenado por la Inquisición por acusaciones de criptojudaísmo, ha sido incluido por algunos críticos (I.S. Révah y algunos más) entre los escritores del Sefarad. En lo tocante a las similitudes con Alarcón, hay que reparar en esa punta de iceberg que es Mudarse por mejorarse, comedia atribuida a Zárate Castro Novo en la Parte diez y nueue de comedias nueuas y escogidas de los meiores ingenios de España..., en Madrid, por Pablo de Val, a costa de Domingo Palacio y Villegas..., 1663, h. 172v. Las similitudes con la comedia de Ruiz de Alarcón tocan al título más que a la obra.

De acuerdo con la fe de bautismo de Alarcón, publicada por Leopoldo Carranco Cardoso, cronista de la ciudad de Taxco, el matrimonio de los padres se celebró en la Ciudad de México en marzo de 1572. Juan nacería a fines del mismo año, siendo bautizado el 30 de diciembre de 1572 en la Ermita de la Santa Veracruz, en el pueblo de Tlachco o Taxco el Viejo. Habiendo sido el primogénito de la pareja formada por Pedro Ruiz de Alarcón y Leonor de Mendoza no llevó el nombre de su padre sino el del santo más cercano en el calendario, san Juan Evangelista, que se festeja el 27 de diciembre. Pudo haber pasado parte de su infancia (ocho años quizás) recluido por la familia, debido a su defecto físico, en algún lugar cerrado, en un sitio próximo a las minas. De ahí, posiblemente, que una de sus primeras obras, La cueva de Salamanca transcurra en un socavón como una suerte de proyección inconsciente: es el lugar en donde el sabio Enrico, alter ego del autor, práctica la magia artificiosa. Vendría a ser la cueva un espacio antropomórfico, según ha señalado el crítico Jaime Concha ${ }^{6}$. Podemos añadir: en donde el niño Alarcón habría podido superar «metafóricamente» el encierro forzado mediante el artificio de la fantasía: quizás lecturas proporcionadas por el padre venido de España, de familia hidalga conquense, que no era minero sino recaudador de alcabalas. La cueva, en la comedia, vendría a ser la metáfora de la reclusión, del hábitat del mago, o del niño contrahecho. Una vez que la familia se trasladó a la Ciudad de México, en 1580-81, Alarcón no hubo de seguir oculto, pudo tener incluso estudios universitarios. En 1600, concluidos estos en la Real y Pontificia Universidad de México, obtuvo una beca de parte de un pariente magnánimo, Gaspar Ruiz Montoya, para seguir estudiando en la Universidad de Salamanca, de octubre de 1600 a noviembre de 1604, según consta en libros de matrícula salmantinos; vivió en Salamanca, visitó Murcia y permaneció algunos años en Sevilla, litigando, antes de embarcarse de regreso a Indias, en 1608, a México, en donde obtuvo el grado de Licenciado en Leyes (febrero de 1609) y permaneció hasta 1613. En este periodo, que pueden considerarse los «oscuros años mexicanos» en razón del rechazo a sus pretensiones de obtener un puesto en la Universidad, y quizás en el gobierno virreinal, debió escribir alguna comedia: El semejante a sí mismo. O bien completar La cueva de Salamanca, ini-

6. Concha, 1981, pp. 24 y 51 
ciada posiblemente en los últimos años de su estancia en la ciudad, como recuerdo preciado de ella y de ese momento de su vida. Su viaje de regreso a España, en 1613 y 26 años de residencia en la Península, lo pusieron en contacto con el mundo de la escena, los escritores que lo antagonizaron (Lope de Vega, Tirso de Molina, Vélez de Guevara, Mira de Mescua, Castillo Solórzano, Cristóbal Suárez de Figueroa entre otros) y los «mentideros» madrileños. Fue objeto de sátiras y pullas, del sabotaje de su comedia El Anticristo, (acto semejante en su violencia y consecuencias para el autor, a una condena, a un auto de fe); víctima del acoso de un mundo mayoritariamente hostil. Equivalente, guardando obvias distancias, al que sufriera Zárate Castronovo por parte del Santo Tribunal. De un modo u otro, ambos fueron hombres zaheridos, perseguidos. El don de raciocinio de Alarcón, su discreción y el relativo apartamiento en que vivió le permitieron protegerse, dedicarse al oficio de autor de comedias en tanto le llegaba el ansiado puesto de relator en el Consejo de Indias entre 1624-1626. Permaneció en él algún tiempo, moviéndose en el ambiente de relatores y burócratas del Consejo. Se retiró después de 1630. Durante 20 años había vivido en concubinato con Ángela de Cervantes y procreado una hija, Lorenza, a la que enseñó a leer y legó sus bienes. Tras dictar testamento el $1^{\circ}$. de agosto, murió en su casa de la calle de las Urosas el 4 de agosto de 1639, y fue enterrado en la Iglesia de San Sebastián. En el testamento ${ }^{7}$ hace constar que deja dinero para que se digan 500 misas por su alma y el alma de sus padres. Hasta aquí se muestra cristiano ortodoxo. Sin embargo, no expresa deseo de ser enterrado con algún hábito, el de San Francisco por ejemplo, como Cervantes. Estamos ante un hombre laico. Al final de su vida, a decir de su crítico Juan Eugenio Hartzenbusch, tenía casa, coche y tertulia. Ésta la integraban colegas del Consejo de Indias, entre ellos nada menos que Antonio de León Pinelo, luego Gran Canciller y albacea en el testamento del dramaturgo. Y al igual que Juan Ruiz de Alarcón, descendiente de una familia de judíos conversos que fuera cruelmente diezmada por la Inquisición. Hay que hacer notar la propensión del dramaturgo novohispano a buscar la amistad de miembros de familias de judíos conversos, entre otros Antonio de León Pinelo. Muy probablemente también del hermano de éste, Juan Rodríguez de León (quien emigrara a la Nueva España en el séquito de Juan de Palafox y Mendoza y fuera clérigo en Tlaxcala y Puebla, además de escritor notable); Juan Carmona Tamariz, perteneciente a una prominente familia judeo-conversa de la ciudad de Puebla en Nueva España que, de acuerdo con documentos inquisitoriales, tuvo ruidos con el Santo Oficio. Fue Carmona Tamariz amigo de Alarcón en Salamanca y prestó testimonio en Sevilla sobre el escritor, al embarcarse éste rumbo a Indias en 1608. El mapa familiar de Alarcón se ve salpicado por las presencias judaicas; en esto se emparenta con Enríquez Gómez. Los abuelos del escritor novohispano, Hernán Hernández de Cazalla (Mendoza) y María de Mendoza, primos entre sí, provenían de familia de comerciantes judíoconversos y fueron primeros pobladores de la Nueva España a mediados del siglo XVI. Por esto último los nietos pudieron reclamar posteriormente mercedes a la Corona. Mineros prósperos en Taxco, tuvieron relaciones de amistad con españoles notables: el hermano y el hijo del virrey Luis de Velasco; oidores, 
tal como Luis de Villanueva; Alonso de Villaseca, el hombre más rico de la Ciudad de México en los mediados del XVI. Cuatro personajes estos, testigos de la boda de los padres de Juan: Leonor de Mendoza y Pedro de Alarcón, en marzo de 1572. En lo tocante a los hijos de la pareja, reparamos en actitudes opuestas respecto a la religión cristiana que conducen a una conclusión: los antecedentes judaicos de la familia. En el caso de Gaspar, tercer hijo, son evidentes las raíces semitas. Cura beneficiado en la región de Taxco a principios del siglo XVII, fue denunciado ante el Santo Oficio por proposiciones indebidas en un sermón al referirse a Dios y la creación del mundo a la ligera y comparar el misterio de la transustanciación de la sangre de Cristo con la técnica de desangrar a un buey al matarlo para poder consumirlo, en una descripción que recordaba la técnica kosher. En la denuncia contra Gaspar presentada al Tribunal por el sacerdote Andrés Girón se afirmaba que un antepasado (el abuelo minero Hernando de Mendoza o Cazalla, sin duda), un «fulano», había sido quemado ${ }^{8}$. Lo cual no se sabe de cierto sucediera aunque sí que el abuelo Hernán tuvo problemas con el Santo Oficio por amancebamiento con una joven india, según W.F. King 9 . Hernando, otro de los hermanos del escritor, también sacerdote, al contrario de Gaspar se caracterizó por su celo extremado en cuestiones religiosas, la inmisericorde delación y condena de la idolatría y de las supersticiones indígenas. Fue un auténtico perseguidor, o «fiscal» de indios en la región de Tenango y Taxco hacia 1618. Escribió un tratado: Idolatrías y supersticiones de los indios... para satisfacer la petición del arzobispo Pérez de la Serna. Una especie de «martillo para las brujas» como los redactados por Sprenger, Martín del Río o Pedro Ciruelo. Representa Hernando de Alarcón el papel del descendiente de judíos conversos al servicio de la religión cristiana, que al comportarse como perseguidor de los naturales idólatras pretende alejar de sí toda sospecha de heterodoxia.

En Juan Ruiz de Alarcón, en cambio, el influjo de una ascendencia judaica no se hace patente en dichos impropios, como en su hermano Gaspar; o en patologías persecutorias, como las de Hernando, sino en los conocimientos relacionados con la cábala, la magia y la astrología. Sabiduría ancestral soslayada, contenida por la mesura, la prudencia. Escribe, sin embargo, dos comedias de magia - La cueva de Salamanca, La prueba de las promesas - que revelan al estudioso versado en la magia natural, artificiosa y demoniaca, como la descrita en los «martillos» o tratados usuales, que lo lleva a deslizarla dentro de la comedia en el fragmento del debate al modo salmantino entre Enrique de Villena y un catedrático. Hay asimismo elementos de magia en otras comedias, como La manganilla de Melilla (magia artificiosa, de tramoya), curiosa obra que tiene como escenario el norte de África

8. Ver Documentos inquisitoriales referentes a Gaspar Ruiz de Alarcón en Peña, 2000, pp. 261-264; a Hernando Ruiz de Alarcón, en Peña, 2000, pp. 260-261 y 264-265. El primero, cura beneficiado en Nochistepec, denunciado ante la Inquisición por proposiciones poco ortodoxas durante la misa dominical; el segundo, por el contrario, celoso defensor de la ortodoxia católica, perseguidor de las supersticiones y del consumo del ololiuhqui, un alucinógeno usado por los indios para la adivinación. Escribió un Tratado de las idolatrías y supersticiones de los indios por encargo del arzobispo Pérez de la Serna hacia 1618, antes de que el arzobispo se embarcara hacia España a raíz del tumulto de enero de 1624 contra el Virrey Marqués de Gelves.

9. King, 1989, p. 45. 
y las escaramuzas entre españoles y moros ${ }^{10}$. Una comedia, Quien mal anda mal acaba, inspirada en un proceso inquisitorial de la Edad Media, lo conduce al terreno fáustico. Y una más, El Anticristo, comedia milenarista, de tema bíblico, en que se entrelazan y compiten tres religiones: cristianismo, judaísmo e islamismo, con el obligado triunfo de las premisas cristianas encarnadas en el personaje de Sofía, y la aparatosa derrota final del Anticristo lograda con efectos de tramoya que remiten a la magia artificiosa. La obra fue objeto de un acto de sabotaje concertado por escritores enemigos de Alarcón en su estreno en Madrid, 1622, presuntamente Lope de Vega y Mira de Mescua. En realidad, por el historiador conquense Pedro Mártir Rizo, que pretendió involucrar a Lope y perjudicar a Alarcón ${ }^{11}$. En lo tocante a las raíces judaicas, no se sabe que Alarcón haya incurrido en prácticas y ritos propios del marranismo, como los que se atribuyeron a Zaráte Castronovo, -comentados por I.S. Revah, Antonio José Sarabia y algunos más- al que en los varios procesos a que le sometió la Inquisición de Toledo y Sevilla se le acusa justamente de marranismo y varios testigos ven en él «culpas e indicios de judaísmo». Aseguran que «guarda los sábados en casa de su tío Antonio Henríquez de Mora poniéndose vestido de gala», y se le sentencia a ser relajado en estatua. Asimismo, en las declaraciones se afirma que observa «en su casa todo lo que hacían en las ceremonias hebreas», y se le define como «judío judaizante en Ruan» ${ }^{12}$.

Volviendo a Ruiz de Alarcón, hay que decir que a manera de protección de su identidad a medias judía, a lo largo de su vida ensaya actitudes y conductas defensivas. Disimula y miente. Oculta, por ejemplo, el lugar de su nacimiento al inscribirse en libros de matrícula de la Universidad de Salamanca, como alguien nacido en México, o en la Ciudad de México en Indias, cuando sabemos que esto sucedió en el pueblo minero de Tetelcingo-Teotalco-Taxco. Nunca revela su edad verdadera asentando, en documentos oficiales, ser más joven de lo que era, señalando vagamente que tiene más de tantos años y menos de tantos (más de 20 y menos de 25, como consta en una carta poder que otorga en Salamanca en 1602, cuando debía tener, en realidad, 28). Vive discretamente su relación de amancebamiento, entre 1616 y 1636, con Ángela de Cervantes, a quien la crítica ha reducido quizás equivocadamente, a mera ama de llaves: vivir amancebado era un delito castigado por la Inquisición, mejor hacerla pasar por persona de servicio. Las inexactitudes en cuanto al lugar de nacimiento podrían relacionarse con varias cosas: el genuino deseo de haber visto la luz en la prestigiada Ciudad de México, ya que un pueblo recóndito llamado «Tetelcingo Tlachco» poco diría a los funcionarios de la Universidad, y a sus condiscípulos; y lo de la edad, la ambigüedad, tendría su origen en haber iniciado tardíamente sus estudios y el hecho descorazonador de no conseguir el empleo anhelado conforme pasaban los años y envejecía, con la joroba a cuestas; al no existir en la época las actas de nacimiento resultaba sencillo alterar la

10. La comedia es considerada patrimonio local en la propia Melilla. Se escenifica con apoyo oficial una vez al año.

11. Bien sabía Ruiz de Alarcón lo que decía al calificar a autores y cómicos de «aplebeyada gente de teatro» en el Prólogo a uno de sus dos tomos de comedias.

12. 12 AHN Inq. Leg. 2996, exp. s/n. Carta del Tribunal de Sevilla al Consejo de la Suprema Inquisición, del 17 de abril de 1663, en Boeglin, en prensa. 
propia edad. 0 bien a un motivo más profundo: negar los primeros 8 o 9 años de su existencia en que pudo haber sido ocultado por la familia en el interior de su casa - sótano, azotea-, o un lugar cerrado. Así, en realidad «nacería» al mundo cuando la familia emigró a México, entre 1580 y 1581. Al abandonar Taxco tuvo educación, incluso llegó a ingresar a la Real y Pontificia Universidad y terminó los cursos de bachiller en Cánones para recibir el título a poco de su llegada a Salamanca, iniciando de inmediato los estudios de Leyes. Se sabe que, pese a su defecto físico era inquieto como una ardilla, diligente al punto de vigilar de lejos los asuntos financieros de la madre viuda Leonor, abogados y notarías de por medio. El disimulo forzado respecto a la condición de descendiente de judíos conversos se relacionaría con el temor no sólo al Santo Oficio, sino incluso a la mera delación. De ahí, quizás, su empeño en anteponer a su nombre el «don», que tanto irritaba a algunos, como forma de exhibir un limpio origen hidalgo. La burla y escarnio de sus contemporáneos bastante se cebaron en el defecto físico, verbalmente y por escrito a lo largo de las «Décimas satíricas a un poeta que se valía de trabajos ajenos». Las poesías abundaron a partir de la redacción encargada a Ruiz Alarcón por el Duque de Cea, del Elogio descriptivo a las fiestas que la Majestad del Rey Felipe IIII hizo en Madrid a 21 de agosto de 1623 años a la celebración de los conciertos entre el serenísimo Carlos Estuardo, príncipe de Inglaterra, y la serenísima María de Austria, infanta de Castilla. Posteriormente, las décimas satíricas fueron impresas por Joseph Alfay ${ }^{13}$. Se le reprobaba en ellas por la mala calidad de los versos, algunos de los cuales pertenecían a Tirso de Molina, Mira de Mescua, y otros. Este tropiezo, junto con el sabotaje de la representación de El Anticristo fue definitivo en la determinación de abandonar los escenarios madrileños y redoblar los esfuerzos para ser aceptado en el Consejo de Indias, lo que logró hacia 1626, muy posiblemente auxiliado por don Ramiro Felipe de Guzmán, yerno del conde-duque de Olivares, y a lo que se sabe discípulo de Ruiz de Alarcón en una academia madrileña. No gozaría de «los favores del mundo» pero supo «ganar amigos».

Dos retos tuvo Ruiz de Alarcón en su vida: la catástrofe de una doble joroba y los antecedentes judaicos, atenuados, disimulados. En esto último, la diferencia con Fernando Zárate Castronovo (o Antonio Enríquez Gómez) que alardeaba de sus orígenes semitas, es evidente. Adelantándonos, la discreción alarconiana permitió al escritor morir sosegadamente en su casa madrileña de la Calle de las Urosas (ahora calle Luis Vélez de Guevara), en tanto que Zárate Castronovo hubo de concluir su turbulenta existencia en los infames calabozos de la Inquisición sevillana.

No está por demás referirse de modo sucinto al itinerario vital de Zárate Castonovo. Nacido en Cuenca murió en Sevilla, hijo de Diego Enríquez, originario de Quintanar de la Orden y casado con una cristiana vieja, Isabel Gómez. El abuelo paterno fue quemado en Cuenca en 1592, poco antes de que él naciera; su abuela sufrió prisión y al padre se le confiscaron los bienes. Enríquez Gómez frecuentó el círculo de Lope de Vega hacia 1632 y se dice escribió comedias para los corrales, seguramente las que aparecen con su nombre real. De acuerdo con la dura his-

13. Comentarios satíricos creados por diversos autores como parte de un conocido vejamen contrario a Juan Ruiz de Alarcón y su «Elogio descriptivo», ed. Rafael Iglesias, 2001. 
toria familiar, no es extraño que al abandonar posteriormente a su propia familia y negocios en Rouen luego de defraudar junto con un socio, a franceses y judíos, y retornar a España cambiando su nombre por el de Zárate Castronovo, quisiera «mudarse» para reiniciar otra vida. Había escrito un soneto (1635) para las Famas... de Pérez de Montalbán al morir Lope de Vega (1635): «De Antonio Enríquez a la muerte feliz del doctor frey Lope de Vega y Carpio», y seguramente lo rondaba la tentación de escribir bajo un nuevo nombre. De época posterior debe datar la redacción de Mudarse por mejorarse, firmando como Zárate Castronovo. Refugiado en Granada, pasó a Sevilla y durante 12 años vive allí, escribe comedias bajo una identidad falsa. Perseguido, ya lo dijimos, huye del Tribunal del Santo Oficio que lo quema dos veces en efigie, 1651 y 1660, en Toledo y Sevilla respectivamente. Lo prenderán en 1661. Muere en las cárceles del Santo Oficio en Triana, antes de que concluya el proceso, en marzo de 1663.

Terriblemente cruenta debió ser la visión de sí mismo quemado en efigie en Sevilla, dejando aparte Toledo. Sorprende que allí haya permanecido, ocultándose simplemente en su casa, en donde será aprehendido y llevado al Palacio de la Inquisición, en las proximidades del Guadalquivir (Betis famoso). Así, perdida toda esperanza de escapar, Zárate debió dejarse morir - ¿deterioro natural incluida la tortura, determinación intencional? - antes que subir a la hoguera. Y lo logró. Ese 18 de marzo de 1663 consumó su última fuga, burló a sus verdugos. La rebeldía magnífica de Zárate contrasta con la prudencia y cautela de Alarcón, un autor marginado en la escena que murió en su casa de la madrileña calle de las Urosas rodeado, suponemos, de unos pocos amigos del Consejo de Indias y criados a quienes menciona en su testamento y deja dinero para lutos de bayeta, así como una cantidad para misas por su alma y la de sus padres. Actitudes radicalmente distintas. Los comentarios sobran.

No está por demás asomarse al fenómeno del plagio y la imitación, motivación inicial de este trabajo, entre los escritores del Siglo de Oro. Práctica más o menos difundida, podemos citar como ejemplo, el caso de las comedias de Alarcón, imitadas por Lope de Vega: Ganar amigos, con el título Amor pleyto y desafío y La verdad sospechosa como El mentiroso. Respecto a la primera, dice A. Millares Carlo: «Con el título de Amor, pleito y desafío se publicó primeramente esta comedia en 1632, en la Parte veynte y cuatro, apócrifa, de Lope de Vega y atribuida a éste» ${ }^{14}$. En cuanto a la segunda, apareció en la «Parte Veynteidós de las comedias del Fénix de España Lope de Vega y Carpio, Zaragoza... por Pedro Vergés, año de1630» ${ }^{15}$. Esto, sumado a otras imitaciones de comedias alarconianas por autores diversos autorizaría a suponer un plagio, o por lo menos, imitación por parte de Zárate Castronovo. El asunto del plagio y de la imitación o copia, ha sido tratado ampliamente por Kevin Perronat partiendo de la frecuencia con que éste, junto sus variantes, se daba en los escritores áureos ${ }^{16}$. Se refiere, entre otros autores plagiados, a Ruiz de Alarcón.

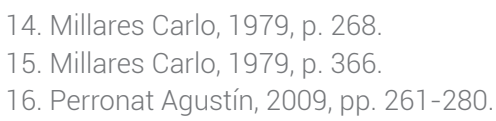


Por lo que toca a una presunta copia de la comedia de Alarcón Mudarse por mejorarse por Fernando Zárate Castronovo sustentada en la pulsión inconsciente de ambos hombres relativa a la identidad, que se refleja en el título (mudarse en hombre normal, de buen talle, sin el lastre de la joroba, Alarcón; mudarse en hombre libre, profesar las creencias que le plazcan, Zárate), hay que decir que éste (16001663), más joven que el novohispano, toma solamente el título de la comedia. Por lo demás, algo frecuente en Enríquez Gómez/Zárate Castronovo, usando uno u otro nombre, es la imitación de comedias ajenas, el préstamo de títulos o fragmentos de otras obras. Ejemplo: «Engañar para reynar», de Pedro Calderón de la Barca (de la que existe un ejemplar en la Biblioteca Menéndez y Pelayo) figura como de Enríquez Gómez en la colección Doze comedias de las más famosas, $3^{a}$. pte [Lisboa], $1649^{17}$. Señalemos que coinciden los nombres de algunos de los personajes: Iberio, Ludovico, Elena, Isabela, Flora, Octavio, con los de la comedia calderoniana. Otra comedia con título de reminiscencias de Calderón, Zelos no ofenden al sol, se imprime con la autoría de Enríquez Gómez, en Lisboa por Pedro Craesbeck, 1653. Se le atribuyó asimismo la Segunda Parte de La hija del aire, desmentida posteriormente. Bajo el nombre de Fernando Zárate Castronovo se conoce la comedia «Los vandos de Rabena y fundación de la Camandula», atribuida a Matos Fragoso en el Catálogo de Mesonero Romanos, de la Biblioteca Histórica de Madrid ${ }^{18}$. Aunque aquí no sabríamos quien imita a quien, ya que Matos Fragoso, nacido en 1608, murió en 1689, 26 años después de Zárate Castronovo. En fin, que imitaciones, plagios, refundiciones, préstamos se configuraron como algo normal en el mundo de la escena y la impresión teatral del XVII. Por otra parte, con el título de Los bandos de Verona, de Rojas Zorrilla, se inauguró hacia 1640 el nuevo teatro del Palacio del Buen Retiro ${ }^{19}$. Es posible que a partir de ésta se originaran las comedias respectivas de Zárate Castronovo y de Matos Fragoso, con un cambio en el título: Ravena por Verona, más como imitación que como plagio.

Acerquémonos a Mudarse por mejorarse en la versión de Zárate Castronovo. En una parte del Primer Acto, los personajes don Carlos y Lirón (gracioso) conversan. Dice Lirón:

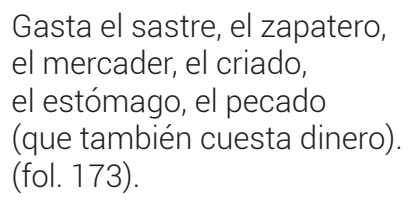

No deja de parecer un tanto libre esta afirmación sobre el «gastar y los dineros». Hasta cierto punto lógica en alguien dedicado al comercio, como Zárate Castronovo. Más adelante hablan el príncipe y César. El diálogo se abre con el encomio del

17. Antonio Enríquez Gómez, Doce comedias las mas famosas que hasta ahora han salido de los meiores y mas insignes poetas: tercera parte.

18. Cerezo Rubio y González Cañal, 2009, p. 88. Nace Juan de Matos Fragoso en Portugal, 1608. Muere mucho después de Zárate Castronovo, en 1689.Se le considera dramaturgo y poeta español de origen portugués.

19. Montoliu Camps, 2002, p. 152. 
amor, la descripción idealizada de la dama; la pasión, el pecado, Luzbel. «Mujeres de ocasión» se dice, hay en la calle, para solaz del Príncipe. Es de notar el realismo en el comentario del personaje del criado que, en otra parte declara, refiriéndose a una mujer: «porque no la hallases sucia». El diálogo con ribetes de picaresca nos acerca a lo relativo al erotismo en la obra de Fernando de Zárate. Algo ajeno al recato alarconiano, aunque también se registre en las comedias de Alarcón el forcejeo de damas y galanes, el asunto del honor ultrajado, el «forzar» a una dama. Concretamente, en La cueva de Salamanca y en Ganar amigos. Lo que cambia de un autor a otro, por lo menos en el ejemplo anterior, es el tono del tratamiento de la mujer.

La comedia de Zárate navegó en el mar de comedias sueltas y encontró acomodo en colecciones y bibliotecas. He podido localizarla físicamente como «suelta» en la Biblioteca de la Facultad de Filología de Granada. Asimismo, registrada con las fichas 5266 y 5267 del Catálogo Sistemático de la Biblioteca Estatal de Berlín, catálogo que, por lo demás, no corresponde a la realidad de las colecciones existentes, saqueadas y empobrecidas a raíz de la Segunda Guerra Mundial. Sin embargo, otra comedia de Zárate, A lo que obligan los zelos, Barcelona, Escuder, ca. 1750, corrió con suerte, forma parte del reducido número de comedias de este acervo que se salvaron. Entre las que, por cierto, no existe físicamente una sola de las varias de Ruiz de Alarcón que se registran en el catálogo ${ }^{20}$.

Un breve epitafio de José Pellicer de Tovar, conocido gacetillero de Madrid, en sus Avisos históricos dio cuenta de la muerte de Ruiz de Alarcón el 4 de agosto de 1639 con un lacónico epitafio: «[Murió] Juan Ruiz de Alarcón, poeta famoso, así por sus comedias como por sus corcobas y Relator del Consejo de Indias» ${ }^{21}$. En cuanto a Antonio Enríquez Gómez (o Zárate Castronovo), una síntesis del último proceso que se le siguió reza como sigue: «Fue preso en 21 de [setiembre] de 61 ». Y más adelante: «enpezó a confesar desde el año de 36 con que incluye las testificaciones del 1er. proceso, y después de confesando más y contra c [óm] plices, y estando la causa conclusa que fue en Marco de 63 , le sobrevino enfermedad y en 18 de Marco le reconciliaron para morir, con que aviendo recivido los sacram[en]tos, murió» ${ }^{22}$. Escuetos epitafios para dos hombres singulares. Algo se puede deducir de ellos respecto a la fama y la época de ambos «poetas»: la marginación denigrante del novohispano; la rebeldía y la infamia inquisitorial en el caso del español.

20. Ver «Noticia de una pérdida: la colección comedias sueltas de Juan Ruiz de Alarcón en la Biblioteca Nacional de Berlín», Peña, 2000, pp. 188-195. En cuanto a Mudarse por mejorarse, de Zárate Castronovo, se le incluye en las colecciones siguientes: Cayetano Alberto de la Barrera Leirado, Bibliografía y biografía del teatro antiguo español, de sus orígenes hasta el siglo XVIII (núms. 6064-67); Dramáticos posteriores a Lope de Vega. Comp. Ramón de Mesonero Romanos, 1924; Tesoro del teatro español desde el siglo XVII hasta nuestros días arreglado y dividido en 4 partes por D. Eugenio de Ochoa 2a. Pte., en Tesoro del teatro español desde su origen (año de 1356) hasta nuestros días arreglado y dividido en 4 partes por D. Eugenio de Ochoa, 1838, I.

21. Ettinghausen, 2012.

22. Domínguez Paz, 2014, p. 47.

HIPOGRIFO, 5.1, 2017 (pp. 357-370) 


\section{BIBLIOGRAFÍA}

Barrera y Leirado, Cayetano Alberto de la, Catálogo bibliográfico y biográfico del teatro antiguo español: desde sus orígenes hasta mediados del siglo XVIII, Alicante, Biblioteca Virtual Miguel de Cervantes, 1999. Disponible en: <http:// www.cervantesvirtual.com/obra/catalogobibliografico-y-biografico-delteatro-antiguo-espanol-desde-sus-origeneshasta-mediados-del-sigloxviii--0/> [19/03/2017].

Boeglin, Michel, Les marranes face a I'Inquisition de Séville au XVI et au XVIIe siecle, Hommage a Claude Mafre, ETILAL, en prensa. (Documentos de la Inquisición de Sevilla.Fragmentos del último proceso contra Antonio Enríquez Gómez).

Castro Leal, Antonio, Juan Ruiz de Alarcón. Su vida y su obra, México, Cuadernos Americanos 2, 1943.

Cerezo Rubio, Ubaldo y Rafael González Cañal, Catálogo de teatro de la Biblioteca Histórica de Madrid. Fondo Mesonero Romanos, Madrid, Ayuntamiento de Madrid, 2009.

Comedias escogidas de diferentes libros de los más célebres e insignes poetas españoles, Bruselas, por Manuel Texera Tartaz, 1704.

Concha, Jaime, «Alarcón, monstruo de Indias. (La cueva de Salamanca)», Revista Iberoamericana, 16, 4, 1981 pp. 69-81.

Domínguez Paz, Elisa, «La polémica Zárate/Enríquez Gómez a propósito de la censura de La conversión de la Magdalena», Cincinatti Romance Review, 37, 2014, pp. 45-66.

Enríquez Gómez, Antonio, Academias morales de las Musas I, ed. Milagros Rodríguez Cáceres y Felipe B. Pedraza Jiménez, Cuenca, Ediciones de la Universidad de Castilla-La Mancha, 2015.

Ettinghausen, Henry, «Pellicer y la prensa de su tiempo», Janus, 1, 2012, <http:// www.janusdigital.es/articulo.htm?id=9> [15/2/2017].

Iglesias, Rafael (ed.), Comentarios satíricos creados por diversos autores como parte de un conocido vejamen contrario a Juan Ruiz de Alarcón y su «Elogio descriptivo», Alicante, Biblioteca Virtual Miguel de Cervantes, 2001. Disponible en: <http://www.cervantesvirtual.com/obra-visor/poemas-satiricos-creadospor-diversos-autores-como-parte-de-un-conocido-vejamenliterariocontrario-a-juan-ruiz-de-alarcon-y-a-su-elogio-descriptivo/html/ ff35a538-82b1-11df-acc7-002185ce6064_11.html> [19/03/2017].

King, Willard F., Juan Ruiz de Alarcón, letrado y dramaturgo. Su mundo mexicano y español, trad. Antonio Alatorre, México, El Colegio de México/Centro de Estudios Lingüísticos, 1989.

Libro de Matrículas, Universidad de Salamanca, Fondo Universitario, AUS 312, 1599/1600. 
Libro de Matrículas, Universidad de Salamanca, Fondo Universitario, AUS 313, 1600.

Mesonero Romanos, Ramón de (comp.), Dramáticos posteriores a Lope de Vega.. Madrid, Librería de los Sucesores de Hernando, 1924.

Millares Carlo, Agustín, Obras completas de Juan Ruiz de Alarcón. II, México, Fondo de Cultura Económica, 1979, 2. ${ }^{\text {a }}$ ed.

Montoliu Camps, Pedro , Enciclopedia de Madrid, Barcelona, Planeta, 2002.

Pedraza Jiménez, Felipe B., Rafael González Cañal y Elena Marcello (ed.), Judaísmo y criptojudaísmo en la comedia española. XXXV Jornadas de Teatro Clásico, Almagro, Cuenca, Ediciones de la Universidad de Castilla-La Mancha, 2014.

Peña, Margarita, Juan Ruiz de Alarcón, semejante a sí mismo. La obra de Ruiz de Alarcón en el espejo de la crítica. Una bibliografía alarconiana, México, Estado de Guerrero, Jornadas Alarconianas V. Sociedad Amigos de Alarcón, 1992.

Peña, Margarita, Juan Ruiz de Alarcón ante la crítica, en las colecciones y los acervos documentales, México, M.A. Porrúa/UNAM/BUAP, 2000.

Perronat Agustín, Kevin, «Cuervos, cornejas y plumas ajenas. Autoría difusa en el teatro del Siglo de Oro», Lemir, 13, 2009, pp. 261-280.

Ruiz de Alarcón, Juan, Parte primera de las comedias de don Juan Ruiz de Alarcón, Madrid, por Juan González, 1628.

VV.AA., Doce comedias las mas famosas que asta ahora han salido de los mejores y mas insignes poetas: tercera parte, Lisboa?, por Antonio Álvarez, 1649?. Disponible en: <http://www.cervantesvirtual.com/obra/doze-comediaslas-masfamosas-que-asta-aora-han-salido-de-los-meiores-y-mas-insignespoetastercera-parte/> [19/03/2017]. 